\title{
Pesquisas com Crianças na Educação Infantil: aspectos éticos e metodológicos nas investigações sobre letramento e identidade étnica-racial
}

\author{
Investigaciones con niños en la Educación Infantil: \\ aspectos éticos y metodológicos en las investigaciones sobre \\ letra y identidade étnico-racial \\ Research with Children in Early Childhood Education: \\ ethical and methodological aspects in the research of \\ literacy and ethnic-racial identity
}

\author{
Lisiane Rossatto Tebaldi ${ }^{1}$ \\ Vanessa Rosa da Costa ${ }^{2}$ \\ Rodrigo Saballa de Carvalho ${ }^{3}$
}

\begin{abstract}
Resumo
O trabalho, a partir do campo dos Estudos da Infância, tem como objetivo discutir os aspectos éticos e metodológicos implicados nas investigações sobre letramento e identidade étnica-racial na Educação Infantil. Metodologicamente, apresenta um mapeamento realizado no site da Biblioteca Digital de Teses de Dissertações (BDTD) a respeito das estratégias de produção de dados presentes em investigações defendidas no período de 2008 a 2018 e seus correlatos cuidados éticos no fazer investigativo. Com base nas análises, o artigo discute as especificidades das investigações com crianças e define, então, três unidades de análise: 1) especificidades da pesquisa com crianças; 2) estratégias de produção de dados presentes nas pesquisas: bricolagens metodológicas; 3) a ética na pesquisa. Com o trabalho, é possível inferir sobre a complexidade das investigações com crianças e, sobretudo, sobre a importância de que sejam conhecidos os modos como as crianças pensam sobre os assuntos que lhes dizem respeito, tendo em vista a qualificação das práticas pedagógicas e a promoção de espaços de maior participação e protagonismo dos pequenos na Educação Infantil.
\end{abstract}

Palavras-chave: Educação Infantil; estratégias ético-metodológicas; identidade étnica-racial; letramento; Pesquisa com Crianças.

\section{Resumen}

El trabajo, a partir del campo de los Estudios de la Infancia, tiene como objetivo discutir los aspectos éticos y metodológicos implicados en las investigaciones sobre letramento e identidad étnica-racial en la Educación Infantil. Metodológicamente, se presenta un mapeo realizado en el sitio de la Biblioteca Digital de Tesis e Disertaciones (BDTD) acerca de las estrategias de producción de datos presentes en investigaciones defendidas en el período de 2008 a 2018 y sus correlatos cuidados éticos presentes en el hacer investigativo. A partir de los análisis, se presenta una discusión acerca de las especificidades de las investigaciones con niños. De este modo,

\footnotetext{
${ }^{1}$ Mestranda em Educação, na Linha de Pesquisa Estudos sobre Infâncias do PPGEDU/UFRGS; Porto Alegre, Rio Grande do Sul, Brasil; lisianetebaldi @ hotmail.com

${ }^{2}$ Mestranda em Educação, na Linha de Pesquisa Educação, Sexualidade e Relações de Gênero do PPGEDU/UFRGS; Porto Alegre, Rio Grande do Sul, Brasil; nessa.7865@ gmail.com

${ }^{3}$ Doutor em Educação -UFRGS, Professor do Programa de Pós-Graduação em Educação -PPGEDU/UFRGS e do Curso de Pedagogia da FACED/UFRGS. Orientador na Linha de Pesquisa Estudos sobre Infâncias do PPGEDU/UFRGS; Porto Alegre, Rio Grande do Sul, Brasil; rsaballa@ etrra.com.br
} 
se definen tres unidades de análisis: 1) especificidades de la investigación con niños; 2) estrategias de producción de datos presentes en las encuestas: bricolajes metodológicas; 3) la ética en la investigación. A partir del trabajo, es posible inferir sobre la complejidad de las investigaciones con niños y sobre todo, acerca de la importancia de que se conozcan los modos en que los niños piensan sobre los asuntos que les conciernen, teniendo en cuenta la calificación de las prácticas pedagógicas y la promoción de espacios de mayor participación y protagonismo de los pequeños en la Educación Infantil.

Palabras clave: Educación Infantil; estrategias ético-metodológicas; identidad étnico-racial; alfabetización; Investigaciones con Niños.

\begin{abstract}
This paper, stemming from the field of Childhood Studies, aims to discuss the ethical and methodological aspects involved in researching on literacy and ethnic-racial identity in Early Childhood Education. Methodologically, a mapping carried out on the site of the Digital Library of Theses of Dissertations (BDTD) is presented regarding the data production strategies present in investigations defended in the period from 2008 to 2018, and their related ethical considerations care present in the investigative process. From the analysis, a discussion is presented about the specificities of the investigations with children. Thus, three units of analysis are defined: 1) specificities of the research with children; 2) data production strategies present in the research: methodological bricolages; 3) ethics in research. From the work, it is possible to make inferences about the complexity of the investigations with children and, above all, about the importance of getting to know the ways in which children think about the subjects that concern them, with a view to the qualification of the pedagogical practices and the promotion of spaces of greater participation, and protagonism of the small ones in the Early Childhood Education.
\end{abstract}

Keywords: Early Childhood Education; ethical-methodological strategies; ethnic-racial identity; literacy; Research with Children.

\title{
1. Introdução
}

[...] os investigadores enfrentam um desafio mais premente e mais intensamente vivido, que é descobrir (GRAUE; WALSH, 2003, p. 10).

O presente artigo é decorrente das leituras e discussões realizadas no Seminário "Prática de Pesquisa em Educação: pesquisa com bebês e crianças pequenas na Educação Infantil" ocorridas durante o segundo semestre de 2018 no Programa de Pós-Graduação em Educação (PPGEDU) da Universidade Federal do Rio Grande do Sul (UFRGS). Também se origina do mapeamento realizado para a composição de um Projeto de Dissertação, na perspectiva da realização de Pesquisa com Crianças, sobre os temas letramento e identidade étnica-racial na Educação Infantil. O intuito é contribuir para a discussão dos aspectos éticos e metodológicos implicados nas investigações com crianças.

Conforme exposto na epígrafe, Graue e Walsh (2003) destacam o grande desafio empreendido pelo investigador ao realizar uma pesquisa, especialmente uma Pesquisa com Crianças. Ouvir as crianças e conhecer seus modos de ser requerem dos pesquisadores uma escuta atenta e sensível, uma atitude reflexiva, uma postura respeitosa e responsável. As crianças têm um papel central nos processos de construção de conhecimentos acerca dos 
modos de ser criança; por essa razão, é importante respeitar, escutar e valorizar sua participação nas pesquisas. Nas palavras de Dornelles e Fernandes (2015, p. 74), "só poderemos capturar o mundo a partir da perspectiva das crianças, se essas nos explicarem, se dispuserem a nos mostrar como veem esse mundo".

Diante do exposto, este artigo apresenta, na primeira seção, as investigações mapeadas no período de 2008 a 2018 sobre Pesquisas com Crianças sobre os temas letramento e identidade étnica-racial na creche e pré-escola. A segunda seção aborda as especificidades da Pesquisa com Crianças. Já a terceira seção apresenta as estratégias de produção de dados presentes nas pesquisas mapeadas, evidenciando bricolagem metodológica. A quarta seção refere-se às questões éticas nas Pesquisas com Crianças. Por sua vez, a quinta seção explicita as considerações finais a respeito do tema.

\section{Pesquisas mapeadas}

A produção do conhecimento não é um empreendimento isolado. É uma construção coletiva da comunidade científica, um processo continuado de busca, no qual cada nova investigação se insere, complementando ou contestando contribuições anteriormente dadas ao estudo do tema (ALVES-MAZZOTTI, 2012, p. 27).

A revisão de bibliografia contribui para que o pesquisador possa situar-se no processo de investigação, ampliando o âmbito e a complexidade da questão investigada. De acordo com Alves-Mazzotti (2012), o mapeamento favorece a busca por novas, enriquecedoras e significativas contribuições sobre o assunto pesquisado, pois, por meio da análise crítica das publicações sobre o tema, pode-se identificar pontos de consenso, controvérsias e possíveis lacunas acerca da investigação.

O levantamento das investigações certamente é um movimento necessário, um exercício de reflexão, um processo que exige tempo, persistência e disciplina por parte do pesquisador. O que foi investigado por outros nos auxilia, encoraja e instiga novas possibilidades. Como afirmam Morosini e Fernandes (2014), um mapeamento das ideias existentes localiza e norteia os passos da investigação, abre inúmeras oportunidades de enriquecimento do estudo e direciona-nos, com mais exatidão, ao que deve ser explorado. Sem dúvida, consiste em um estudo basilar para os futuros passos da investigação pretendida.

Sob tal perspectiva, o mapeamento foi realizado no site da Biblioteca Digital de Teses e Dissertações (BTDT) com o intuito de conhecer as produções atuais publicadas sobre os temas letramento e identidade étnica-racial. Delimitou-se a investigar a área da Educação 
Infantil, no período compreendido entre 2008 e 2018, com enfoque central na busca de Pesquisa com Crianças.

Para o tema letramento, os descritores de busca foram definidos a fim de localizar e examinar teses e dissertações nas quais as narrativas orais das crianças expressassem as relações entre brincar e letrar nos contextos pré-escolares. As pesquisas mapeadas estão expressas no Quadro 1.

\begin{tabular}{|c|c|c|c|c|}
\hline Ano & Título & $\begin{array}{c}\text { Tipo de } \\
\text { documento }\end{array}$ & Autor & Universidade \\
\hline 2009 & $\begin{array}{c}\text { A narrativa oral literária na Educação Infantil: } \\
\text { quem conta um conto aumenta um ponto }\end{array}$ & Tese & $\begin{array}{c}\text { Ana Nery Barbosa } \\
\text { de Araújo }\end{array}$ & $\begin{array}{c}\text { Universidade Federal } \\
\text { de Pernambuco } \\
\text { (UFPE) }\end{array}$ \\
\hline 2015 & $\begin{array}{c}\text { Práticas de letramento de uma turma de pré- } \\
\text { escola em uma escola do campo do Rio Grande - } \\
\text { RS }\end{array}$ & Dissertação & $\begin{array}{c}\text { Leticia de Aguiar } \\
\text { Bueno }\end{array}$ & $\begin{array}{c}\text { Universidade Federal } \\
\text { de Rio Grande } \\
\text { (FURG) }\end{array}$ \\
\hline 2015 & $\begin{array}{c}\text { A imaginação na produção narrativa de crianças: } \\
\text { contando, recontando e imaginando }\end{array}$ & Dissertação & $\begin{array}{c}\text { Débora Cristina } \\
\text { Sales da Cruz } \\
\text { Vieira }\end{array}$ & $\begin{array}{c}\text { Universidade de } \\
\text { Braślia } \\
\text { (UNB) }\end{array}$ \\
\hline 2016 & $\begin{array}{c}\text { As vozes da infância: narrativas e estórias das } \\
\text { crianças em interações em uma UMEI de Belo } \\
\text { Horizonte }\end{array}$ & Dissertação & $\begin{array}{c}\text { Priscila Moura } \\
\text { Bastos Moraes }\end{array}$ & $\begin{array}{c}\text { Universidade Federal } \\
\text { de Minas Gerais } \\
\text { (UFMG) }\end{array}$ \\
\hline
\end{tabular}

Quadro 1 - Teses e dissertações sobre letramento, brincadeira e narrativas orais. Fonte: Elaboração própria (2018).

As quatro investigações, sendo uma tese (ARAÚJO, 2009) e três dissertações (BUENO, 2015; VIEIRA, 2015; MORAES, 2016), abordam o tema do letramento com ênfase nas narrativas orais das crianças pré-escolares. Em sua tese, Araújo (2009) afirma que as narrativas orais literárias são a porta de entrada para o mundo letrado. Por sua vez, Bueno (2015) destaca a oralidade e as interações das crianças como eixos fundantes das práticas letradas em uma turma de pré-escola. Vieira (2015), em sua dissertação, aborda a relação entre a imaginação e a produção das narrativas orais das crianças. Moraes (2016), em sua investigação, analisa a linguagem oral das crianças a partir das narrativas expressas em suas interações no contexto pré-escolar.

No que se refere ao tema de identidade étnica-racial, foram mapeadas três investigações realizadas na perspectiva de Pesquisa com Crianças na Educação Infantil. O Quadro 2, a seguir, apresenta as investigações mapeadas.

\begin{tabular}{|c|c|c|c|c|}
\hline Ano & Título & $\begin{array}{c}\text { Tipo de } \\
\text { documento }\end{array}$ & Autor & Universidade \\
\hline 2014 & $\begin{array}{c}\text { "O meu cabelo é assim... igualzinho o da bruxa, todo } \\
\text { armado": hierarquização e racialização das crianças } \\
\text { pequenininhas negras na Educação Infantil }\end{array}$ & Dissertação & Flávio Santiago & $\begin{array}{c}\text { Universidade } \\
\text { Estadual de Campinas } \\
\text { (UNICAMP) }\end{array}$ \\
\hline 2015 & $\begin{array}{c}\text { "Ser quilombola": identidade, território e educação na } \\
\text { cultura infantil }\end{array}$ & Tese & $\begin{array}{c}\text { Márcia Lúcia } \\
\text { Anacleto de } \\
\text { Souza }\end{array}$ & $\begin{array}{c}\text { Universidade } \\
\text { Estadual de Campinas } \\
\text { (UNICAMP) }\end{array}$ \\
\hline
\end{tabular}


RELACult - Revista Latino-Americana de Estudos em Cultura e Sociedade

\begin{tabular}{|c|c|c|c|c|}
\hline 2016 & $\begin{array}{c}\text { "Solta o cabelo!": etnografia sobre o cabelo crespo } \\
\text { como marcador de identidade étnico-racial entre } \\
\text { crianças negras da educação infantil }\end{array}$ & Dissertação & Aline de & $\begin{array}{c}\text { Universidade } \\
\text { Oliveira Braga }\end{array}$ \\
$\begin{array}{c}\text { Estadual do Rio de } \\
\text { Janeiro } \\
\text { (UERJ) }\end{array}$ \\
\hline
\end{tabular}

Quadro 2 - Teses e dissertações sobre identidade étnica-racial.

Fonte: Elaboração própria (2018).

Das três publicações encontradas, duas são dissertações (SANTIAGO, 2014; BRAGA, 2016), e uma, tese (SOUZA, 2015). Em sua tese, Souza (2015) aborda o contexto vivido por crianças quilombolas, discorrendo sobre as experiências infantis construídas em torno do seu território específico. No que tange às dissertações, Santiago (2015) explicita diferentes processos de racialização vividos na creche por crianças negras bem pequenas, e Braga (2016) analisa como o cabelo crespo se torna um marcador de identidade étnica-racial das crianças negras.

Com base no exposto, é possível constatar a escassez de investigações sobre os temas letramento e identidade étnica-racial na Educação Infantil baseadas em uma abordagem metodológica de Pesquisa com Crianças. Martins Filho (2011) salienta que, no Brasil, ainda são incipientes práticas metodológicas de pesquisa que abordam o ponto de vista das crianças, considerando "[...] as crianças como informantes e interlocutoras competentes para falarem de si mesmas durante a coleta de dados" (MARTINS FILHO, 2011, p. 83). Nesse sentido, a seção a seguir aborda as complexidades e singularidades na realização de Pesquisa com Crianças.

\title{
3. As especificidades das Pesquisas com Crianças
}

\begin{abstract}
Descobrir - intelectualmente, fisicamente e emocionalmente é extremamente difícil quando se trata das crianças. A distância física social, cognitiva e política entre o adulto e a criança tornam essa relação muito diferente da relação entre adultos. Na investigação com crianças nunca nos tornamos crianças, mantemo-nos sempre como um "outro" bem definido e prontamente identificável (GRAUE; WALSH, 2003, p. $10)$.
\end{abstract}

Um grande desafio na Pesquisa com Crianças é considerar o ponto de vista das crianças, o que exige do pesquisador certo abandono e superação da perspectiva adultocêntrica. Segundo Moraes (2016, p. 13), "é preciso ouvir o que as crianças têm a dizer para aprendermos um pouco mais com elas e sobre a infância, a experiência que as constitui”. Corroborando o exposto, Martins Filho (2011) afirma que Pesquisa com Crianças é conhecer a(s) infância(s) com base nos jeitos de ser criança, desvelando suas especificidades e considerando seus múltiplos contextos sociais e culturais. 
Assim, a investigação com crianças supõe primordialmente uma imagem de criança potente, protagonista, competente, um sujeito histórico, de direitos e produtor de cultura. Mais do que dar voz às crianças, é preciso escutar, validar o que elas estão dizendo para dar a conhecer à comunidade científica os pontos de vista dessas mesmas crianças sobre a investigação empreendida, pois "as crianças são sujeitos relativamente autônomos, com elaborações próprias a respeito do mundo e representações da sua infância, constituindo-se em importantes sujeitos de pesquisa" (SOUZA, 2014, p. 49).

Nessa perspectiva, Vasconcelos (2016, p. 97-98) declara que a Pesquisa com Crianças traz consigo dilemas específicos, "não só porque os adultos têm as suas próprias percepções sobre as crianças e porque as crianças têm uma posição 'marginal' na sociedade, mas também porque elas são basicamente diferentes dos adultos". Dessa forma, é tarefa do pesquisador criar contextos nos quais as crianças possam falar e expressar seus pontos de vista acerca do problema em estudo.

A Pesquisa com Crianças requer muitas vezes a exploração de técnicas e instrumentos não convencionais, visto que, "especialmente no caso das crianças pequenas o corpo é o principal instrumento de apreensão e comunicação, [pois] se não falam, apontam, mostram, tocam, evidenciam" (SOUZA, 2014, p. 50). Ainda, segundo Souza (2014), o adulto pesquisador, em quaisquer circunstâncias, enxerga as crianças "por cima ou de cima", destacando a importância desse "abaixar-se" para olhar as crianças nos olhos, estabelecendo, assim, um diálogo, uma aproximação, um encontro. Nas palavras de Souza (2014, p. 60), “o pesquisador tem que estar atento e disposto a correr atrás das crianças, especialmente depois que a curiosidade que as atraíam [...] é vencida e elas retomam seu cotidiano e rotina".

Nesse cenário, Pires (2007, p. 255) salienta que "um dos desafios do pesquisador é conseguir manejar sua presença no campo, de modo que respeite as normas de interação social reinantes", bem como as especificidades do grupo investigado, conseguindo inserir-se no campo de maneira efetiva a fim de realizar satisfatoriamente a pesquisa.

A Pesquisa com Crianças afirma a todo o momento a centralidade das crianças. Os adultos fazem parte do contexto das crianças, mas a investigação visa centralmente às crianças, seus modos de ser e estar no mundo, suas relações e interações com os demais. Para Graue e Walsh (2003, p. 13), “a investigação deve voltar sempre às crianças. Os significados que procuramos são os significados das crianças, não dos adultos". Nesse sentido, é preciso estar atento e ter cuidado para que a voz das crianças não fique subordinada ao discurso do pesquisador. 
Corroborando o exposto, Vasconcelos (2016, p. 110) defende que "as crianças são intérpretes reflexivos, portanto há que respeitar e incluir os seus pontos de vista enquanto atores sociais interpretativos e competentes". Para isso, é importante que o pesquisador utilize variadas estratégias para a geração de dados para que a pesquisa seja realmente realizada com crianças e não apenas sobre elas.

\section{Estratégias de produção de dados presentes nas pesquisas: bricolagem metodológica}

[...] só poderemos capturar o mundo a partir da perspectiva das crianças, se essas nos explicarem, se dispuserem a nos mostrar como veem esse mundo (DORNELES; FERNANDES, 2015, p. 74).

A Pesquisa com Crianças requer proximidade, investigação presencial (GRAUE; WALSH, 2003), escuta atenta e reflexividade (DORNELLES; FERNANDES, 2015; SALGADO; MÜLLER, 2015) por parte do investigador, visto que é preciso captar as diferentes formas de expressividade das crianças. Para tanto, faz-se necessário diversidade de procedimentos metodológicos para a obtenção dos dados para a análise.

O Quadro 3 apresenta a abordagem metodológica e as estratégias para a geração de dados evidenciadas nas quatro pesquisas mapeadas sobre letramento que envolveram as crianças como protagonistas do processo de investigação.

\begin{tabular}{|c|c|c|}
\hline Autor, ano e instituição & Metodologia & Estratégias para a geração de dados \\
\hline ARAÚJO & Abordagem qualitativa & Observação participante \\
2009 & & Procedimento de intervenção \\
UFPE & & Videogravação \\
\hline BUENO & Abordagem qualitativa; & Observaro participante \\
2015 & pesquisa etnográfica com crianças & Registro no caderno de anotações \\
FURG & & Diário de campo \\
& & Filmagens e fotografia \\
& & Entrevistas não diretivas \\
\hline VIEIRA & Pesquisa qualitativa com crianças & Observação participante \\
2015 & & Dinâmicas conversacionais \\
UNB & & Oficinas de histórias \\
& & Reconto oral de narrativas \\
& & Registros pictóricos \\
& & Atividades lúdicas e dramatizações \\
& & Filmagem e gravação de áudio \\
& & Escolha de episódios significativos \\
\hline MORAES & Observação participante \\
2016 & Pesquisa com crianças; & Anotações no diário de campo \\
UFMG & Resquisa qualitativa & Filmagens \\
& & \\
& & \\
\hline
\end{tabular}

Quadro 3 - Metodologia e estratégias para a geração de dados nas pesquisas sobre letramento. Fonte: Elaboração própria (2018). 
No que se refere à metodologia, a análise do Quadro 3 evidencia que as quatro investigações se caracterizam por uma abordagem qualitativa de pesquisa. A abordagem qualitativa enfatiza o caráter subjetivo do objeto analisado, o qual, por sua vez, é estudado em suas particularidades no contexto no qual está inserido.

Cabe destacar que Bueno (2015), Vieira (2015) e Moraes (2016) apontam que suas investigações são Pesquisas com Crianças. Bueno (2015) expressa ainda que sua pesquisa é uma investigação etnográfica.

Ao analisar o Quadro 3, é possível constatar também a diversidade de estratégias exploradas pelas pesquisadoras (ARAÚJO, 2009; BUENO, 2015; VIEIRA, 2015; MORAES, 2016) para a geração dos dados, pois a ciência interpretativa, conforme denominado por Graue e Walsh (2003), indica que, para compreender bem as crianças, é preciso combinar várias abordagens.

Estar com as crianças e conhecer suas especificidades, seus modos de ser e estar no mundo requerem, do pesquisador, tempo, paciência, sensibilidade, aproximação, uma postura ética, atenta e respeitosa. Nas palavras de Vasconcelos (2016), não basta "estar lá", é necessário "estar com".

O Gráfico 1, a seguir, explicita as diversas estratégias empregadas nas investigações.

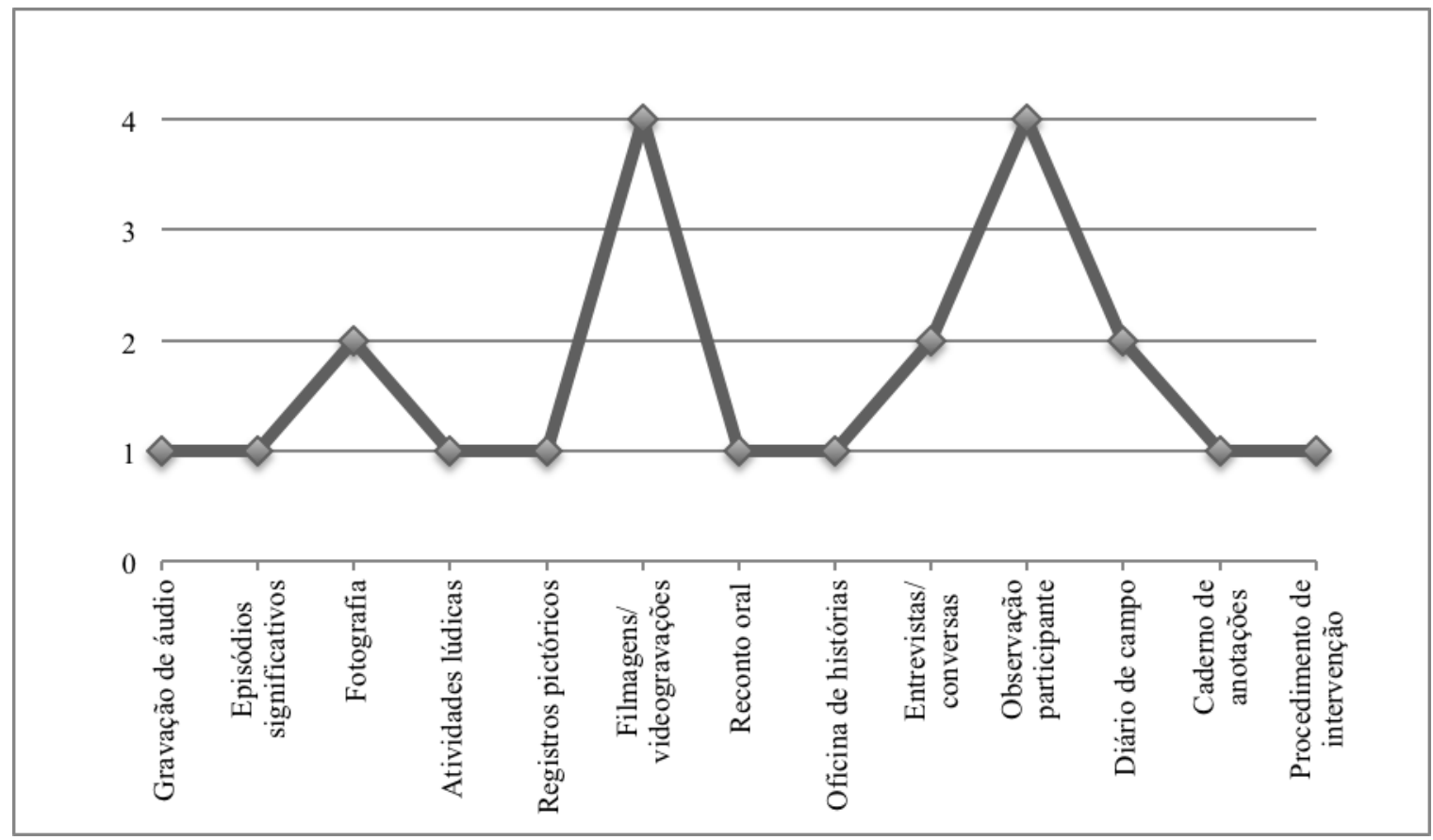

Gráfico 1 - Estratégias para a geração de dados nas pesquisas sobre letramento. Fonte: Elaboração própria (2018).

Quanto às estratégias para a geração do material de análise nas investigações sobre letramento, evidenciam-se múltiplas possibilidades: observação participante, filmagens e 
videogravações, entrevistas e conversas, diário de campo, registros fotográficos, caderno de anotações, gravação de áudio, episódios significativos, atividades lúdicas, registros pictóricos, reconto oral, oficina de histórias, procedimento de intervenção.

A partir do exposto, Pires (2007, p. 247) sublinha que "diferentes técnicas de pesquisa podem apresentar resultados complementares", contribuindo para a maior eficácia na análise dos dados gerados. Assim, pode-se constatar que as pesquisadoras (ARAÚJO, 2009; BUENO, 2015; VIEIRA, 2015; MORAES, 2016) buscaram se inserir no contexto de vida cotidiana das crianças. O uso de diferentes estratégias de geração de dados, de acordo com Pires (2007), pode trazer resultados complementares, pois os mundos do pesquisador, enquanto adulto, e o do nativo, enquanto criança, são comunicáveis. Dessa maneira, a diversidade de procedimentos e estratégias gera possibilidades complementares para o refinamento da análise dos dados coletados.

No que se refere às pesquisas mapeadas sobre identidade étnica-racial, o Quadro 4 apresenta a abordagem metodológica e as estratégias para a geração de dados.

\begin{tabular}{|c|c|c|}
\hline Autor, ano e instituição & Metodologia & Estratégias para a geração de dados \\
\hline SANTIAGO & Etnografia & Gravação \\
2014 & & Diário de campo \\
UNICAMP & & Observação participante \\
\hline SOUZA & Etnografia & Diário de campo \\
2015 & & Observação \\
UNICAMP & & \\
\hline BRAGA & Etnografia & Diário de campo \\
2016 & & Observação \\
UERJ & & Gravação \\
\hline
\end{tabular}

Quadro 4 - Metodologia e estratégias para a geração de dados nas pesquisas sobre identidade étnica-racial. Fonte: Elaboração própria (2018).

A análise do Quadro 4 mostra que as três investigações (SANTIAGO, 2014; SOUZA, 2015; BRAGA, 2016) são de caráter qualitativo, com base em uma abordagem etnográfica.

A partir do exposto, Santiago (2015) aponta que a pesquisa de caráter etnográfico é feita de encontros que permitem o convívio, a escuta e a aprendizagem constante no campo, desenraizando preconcepções de sujeito, sociedade e relações sociais. $\mathrm{O}$ autor ainda enfatiza que os resultados coletados nesse espaço de investigação são fruto da intersecção do universo do pesquisador e do campo de pesquisa.

É importante reconhecer a mediação do adulto, enquanto pesquisador, no processo de dar visibilidade aos pontos de vista e contribuições das crianças. Santiago (2015) destaca a importância de as crianças serem ouvidas para que se possa construir uma educação para as relações étnico-raciais no campo da Educação Infantil. Para tanto, segundo Santiago (2014), a Pesquisa com Crianças requer um "olhar atento" às múltiplas linguagens das crianças 
expressas em suas culturas infantis. Sob tal perspectiva, Dornelles e Fernandes (2015, p. 73) evidenciam que dar autoria às crianças implica nos "aventurarmos para fora do que nos é reconhecível e sustentarmos como investigadores, a autoria composta entre nós adultos e crianças".

Nesse sentido, Souza (2015) salienta que pesquisar crianças envolve o aprofundamento das questões metodológicas nas pesquisas com "o outro", convocando o pesquisador a indagar a própria produção de conhecimento sobre a criança em nossa sociedade e no pensamento científico, uma vez que "ouvir as crianças e compreender o que dizem de diferentes maneiras é afirmar que elas também são confiáveis" (SOUZA, 2015, p. 21).

Corroborando o exposto, Salgado e Müller (2015) afirmam que há interesse e um crescente compromisso em incluir a infância nas pesquisas, a fim de capturar as ideias e pontos de vista das crianças sobre temas que são importantes para elas.

Assim, o Gráfico 2, a seguir, explicita as estratégias empregadas para a geração de dados nas investigações sobre identidade étnica-racial.

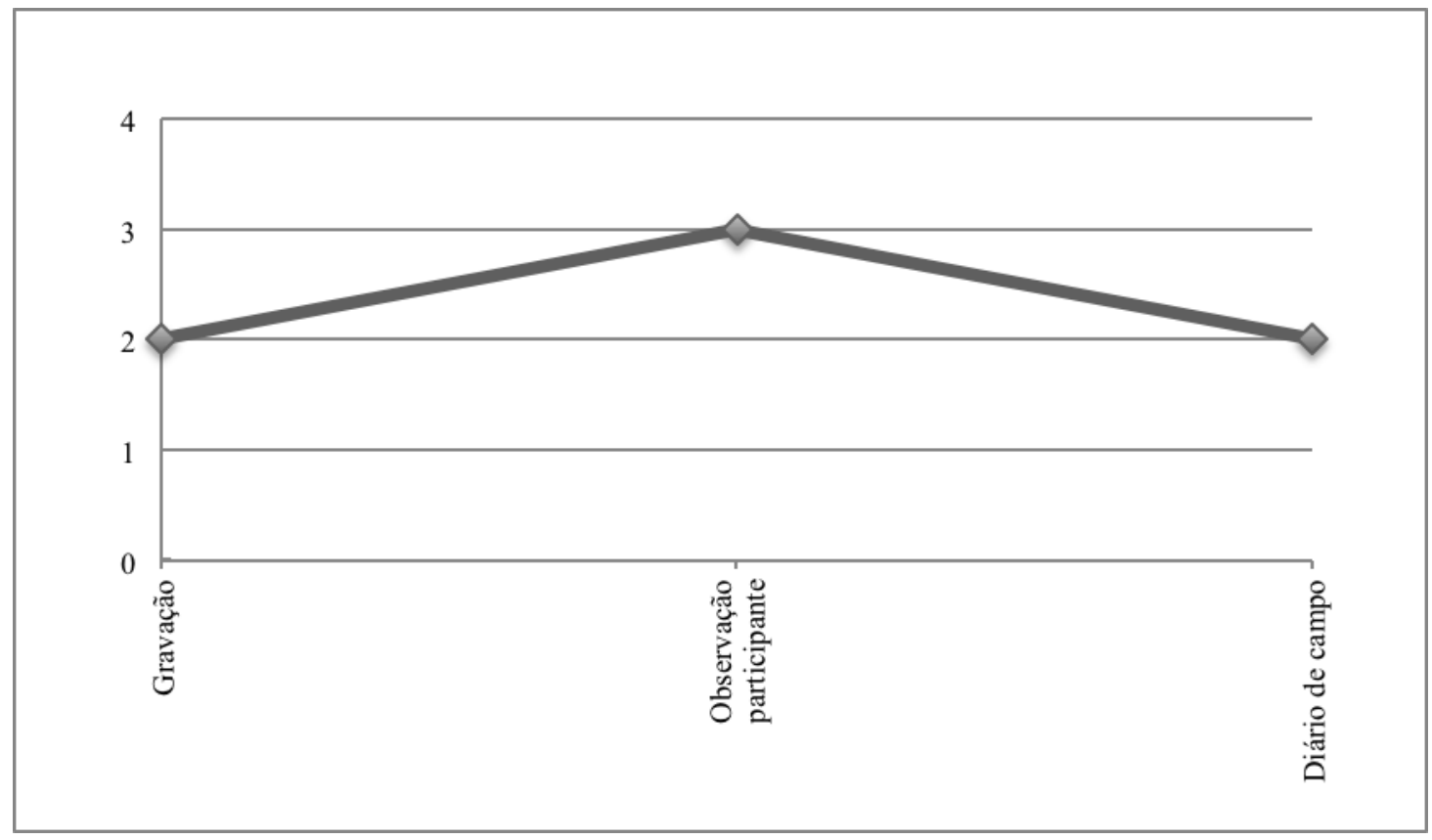

Gráfico 2 - Estratégias para a geração de dados nas pesquisas sobre identidade étnica-racial. Fonte: Elaboração própria (2018).

Com relação às estratégias de geração de dados (GRAUE; WALSH, 2003), ao analisar as investigações sobre identidade étnica-racial, evidencia-se: observação participante, gravação e diário de campo. A observação participante foi uma estratégia presente em todas as investigações mapeadas e caracteriza-se pelo envolvimento direto do investigador com o 
grupo pesquisado. Para Vasconcelos (2016, p. 60), a observação participante é a "tentativa de tornar significativo o mundo estudado na perspectiva dos que estão a ser observados", é estar simultaneamente "dentro" e "fora" do contexto da pesquisa. Para isso, é preciso "olhar as mesmas coisas vezes sem conta até que elas comecem a falar por si” (VASCONCELOS, 2016, p. 61).

A Pesquisa com Crianças requer do pesquisador ir além do que é audível, perceber os mundos não falados, ouvir o que as crianças não respondem, em uma perspectiva de respeito pela voz delas, refletindo acerca das complexidades que enquadram o que dizem. Essa reflexividade (DORNELLES; FERNANDES, 2015; SALGADO; MÜLLER, 2015) por parte do pesquisador propicia credibilidade às crianças como atores centrais da investigação e assegura a conduta ética na pesquisa.

\section{A ética na Pesquisa com Crianças}

[...] é essencial escutar as crianças [...] elas podem ser membros ativos dos processos de investigação que fazemos sobre elas, de modo a que a investigação seja feita com elas (VASCONCELOS, 2016, p. 93).

Considerando as pesquisas selecionadas no mapeamento, no que tange aos aspectos éticos, Araújo (2009) destaca que houve consentimento dos responsáveis, que sua pesquisa foi submetida ao Comitê de Ética e que os resultados obtidos foram comunicados e discutidos com a equipe de profissionais da instituição pesquisada. Por outro lado, a pesquisadora não faz referência ao assentimento das crianças, nem traz referências teóricas sobre o assunto. $\mathrm{Na}$ dissertação de Bueno (2015), também não se evidencia explicitamente a dimensão ética de uma pesquisa envolvendo crianças.

Por sua vez, Vieira (2015) ressalta o cuidado com os aspectos éticos de sua investigação. Na dissertação, descreve com pormenores o percurso envolvendo as crianças: o primeiro contato, o diálogo com as crianças, o convite, a reunião com as famílias após a definição das crianças "colaboradoras" da pesquisa, o termo de consentimento assinado pelos responsáveis. Outro detalhe a frisar é a escolha, pelas próprias crianças, dos "nomes fictícios", inspirados em personagens da literatura infantil, preservando, assim, a identidade delas.

Vieira (2015) ainda traz, em sua dissertação, referenciais a respeito de uma pesquisa com crianças: cita Campos (2008), sobre a importância de "dar voz" às crianças; e Silva, Barbosa e Kramer (2008), sobre o desafio de ver (observar, construir o olhar, reeducar o olho) 
e ouvir (captar e procurar entender, escutar o dito e o não dito, valorizar a narrativa) com sensibilidade todas as relações e interações em uma investigação de campo com crianças.

Da mesma forma, Moraes (2016) enfatiza a relevância da dimensão ética em uma Pesquisa com Crianças. Conforme citado anteriormente, os nomes das crianças foram substituídos, de acordo com a escolha delas mesmas, com a intenção de resguardá-las. A pesquisadora buscou o consentimento não apenas dos responsáveis, mas também das crianças. Apresenta questões éticas fundamentadas na concepção de criança como sujeito de direitos, citando Kramer (2002) e Barbosa (2009).

Assim, a partir da leitura analítica das pesquisas mapeadas, evidencia-se a importância e o cuidado ético ao realizar uma Pesquisa com Crianças. Nas palavras de Graue e Walsh (2003, p. 115), é fundamental considerar a investigação com crianças um modo disciplinado e sistemático de conviver com crianças que sabem mais acerca do seu mundo do que o investigador.

Realizar Pesquisa com Crianças requer fundamentalmente um cuidado ético. Entrar na vida de outras pessoas é tornar-se um intruso; portanto, é necessário obter permissão, que vai além de simplesmente obter consentimento. É importante negociar com as crianças todos os aspectos e etapas das investigações, desde a entrada no campo, os objetivos e quais crianças querem participar da pesquisa e contribuir para a coleta de dados (DELGADO; MÜLLER, 2005, p. 355). Segundo Delgado e Müller (2005), no Brasil, ainda temos um longo caminho a percorrer no que se refere às Pesquisas com Crianças, suas experiências e culturas.

\section{Considerações finais}

Ao inventarmos modos de pesquisa com crianças, tentamos nos afastar do que somos até então e, quem sabe, a partir desse encontro abandonemos a tranquilidade que vivemos, entendendo que nossas crianças escapam, são sempre para nós um enigma e, quem sabe com isso, tenhamos presente que a toda nova investigação com crianças ousemos nos reinventar como pesquisadores de crianças (DORNELLES; FERNANDES, 2015, p. 74).

O presente artigo, com o intuito de contribuir para a discussão acerca dos aspectos éticos e metodológicos implicados nas investigações com crianças, apresenta considerações relevantes para os pesquisadores que buscam conhecer os modos de ser da infância contemporânea.

A complexidade que envolve a Pesquisa com Crianças requer do pesquisador escuta atenta e sensível (GRAUE; WALSH, 2003; DORNELLES; FERNANDES, 2015; 
SALGADO; MÜLLER, 2015), reflexividade, presença efetiva e proximidade com o campo investigado, construindo uma relação de reciprocidade e respeito com as crianças.

Outro aspecto importante a destacar é a centralidade das crianças na pesquisa, o desafio de sempre evidenciar o ponto de vista das crianças, e não dos adultos. Para isso, é fundamental a imagem de criança capaz, sujeito de direitos e produtor de cultura. As crianças são informantes e interlocutores competentes (MARTINS FILHO, 2011), intérpretes reflexivos, atores sociais interpretativos e competentes (VASCONCELOS, 2016), sujeitos potentes de participação (DORNELLES; FERNANDES, 2015), sabem muito e têm muito a comunicar acerca do seu mundo e dos seus contextos de vida cotidiana.

Sob tal perspectiva, para que o pesquisador possa realmente conhecer o que as crianças têm a dizer sobre o assunto investigado, é de crucial importância o emprego de variados procedimentos, diferentes técnicas e estratégias para a geração de dados, considerando os múltiplos contextos sociais e culturais das crianças. É preciso observar, de perto e sistematicamente, as crianças em seus contextos locais, prestar "atenção às 'particularidades concretas' das suas vidas nestes contextos” (GRAUE; WALSH, 2003, p. 21) e registrar tudo ao mais ínfimo pormenor.

Para isso, cabe reiterar a relevância do assentimento das crianças quanto à sua participação na pesquisa, pois, de acordo com Vasconcelos (2016), as crianças encontram-se em dupla situação de vulnerabilidade: são crianças e são sujeitos e instrumentos da investigação. Nesse entendimento, faz-se necessário um cuidado redobrado, já que "a relação de poder adulto-criança é obviamente desigual, mas as crianças não são seres 'menores'. A investigação deve ter uma atenção lúcida, sensata e cuidadosa a esse fato" (VASCONCELOS, 2016, p. 112). Dessa forma, destaca-se a pertinência dos cuidados éticos ao se empreender uma Pesquisa com Crianças.

Certamente, “investigar com crianças pressupõe cruzar calmarias e tempestades, traçar cartografias que [envolvem] metas, mudanças de rotas, retomadas e novos caminhos e, isso, nós aprendemos com as crianças em nossas pesquisas" (DORNELLES; FERNANDES, 2015, p. 74, grifos nossos).

Graue e Walsh (2003, p. 141) traduzem a complexa, desafiadora e bela tarefa empreendida pelo pesquisador em uma Pesquisa com Crianças: "Esteja atento. Seja paciente. Seja persistente".

\section{Referências}


ARAÚJO, A. N. B. A narrativa oral literária na Educação Infantil: quem conta um conto aumenta um ponto. 2009. 201 f. Tese (Doutorado em Educação) - Universidade Federal de Pernambuco, Recife, 2009.

BRAGA, A. O. "Solta o cabelo!": etnografia sobre o cabelo crespo como marcador de identidade étnico-racial entre crianças negras da Educação Infantil. 2016. 139 f. Dissertação (Mestrado em Educação, Comunicação e Cultura em Periferias Urbanas) - Faculdade de Educação da Baixada Fluminense, Universidade do Estado do Rio de Janeiro, Duque de Caxias, 2016.

BUENO, L. A. Práticas de letramento de uma turma de pré-escola em uma escola do campo no município do Rio Grande - RS. 2015. 129 f. Dissertação (Mestrado em Educação) Universidade Federal de Rio Grande, Rio Grande, 2015.

DELGADO, A. C. C.; MÜLlER, F. Sociologia da Infância: pesquisa com crianças (Apresentação). Educação e Sociedade, Campinas, v. 26, n. 91, p. 351-360, maio/ago. 2005.

DORNELLES, L. V.; FERNANDES, N. Estudos da Criança e Pesquisa com Crianças: nuances luso-brasileiras acerca dos desafios éticos e metodológicos. Currículo sem Fronteiras, v. 15, n. 1, p. 65-78, jan./abr. 2015. Disponível em: http://www.curriculosemfronteiras.org/vol15iss1articles/dornelles-fernandes.pdf. Acesso em: 09 dez. 2018

GRAUE, E.; WALSH, D. Investigação etnográfica com crianças: teorias, métodos e ética. Lisboa: Fundação Calouste Gulbenkian, 2003.

MARTINS FILHO, A. J. Jeitos de ser criança: balanço de uma década de pesquisas com crianças apresentadas na Anped. In: MARTINS FILHO, Altino José. Das pesquisas com crianças à complexidade da infância. Campinas: Autores Associados, 2011.

MORAES, P. M. B. M. As vozes da infância: narrativas e estórias das crianças em interações em uma UMEI de Belo Horizonte. 2016. 110 f. Dissertação (Mestrado Profissional em Educação e Docência) - Faculdade de Educação, Universidade Federal de Minas Gerais, 2016.

MOROSINI, M. C.; FERNANDES, C. M. B. Estado do Conhecimento: conceitos, finalidades e interlocuções. Educação por escrito. Porto Alegre, v. 5, n. 2, p. 154-164, jul./dez. 2014

PIRES, F. Ser adulta e pesquisar crianças: explorando possibilidades metodológicas na pesquisa antropológica. Revista de Antropologia, São Paulo, v. 50, n. 1, p. 225-270, jan./jun. 2007.

SALGADO, M. M.; MÜLLER, F. A participação das crianças nos estudos da infância e as possibilidades da etnografia sensorial. Currículo sem Fronteiras, v. 15, n. 1, p. 65-78, jan./abr. 2015.2 Disponível em: http://www.curriculosemfronteiras.org/vol15iss1articles/muller-salgado.pdf. Acesso em: 09 dez. 2018.

SANTIAGO, F. Gritos sem palavras: resistências das crianças pequenininhas negras frente ao racismo. Educação em Revista, Belo Horizonte, v. 31, n. 2, p. 129-153, abr./jun. 2015. 
SANTIAGO, F. "O meu cabelo é assim... igualzinho o da bruxa, todo armado": hierarquização e racialização das crianças pequenininhas negras na Educação Infantil. 2014. 127 f. Dissertação (Mestrado em Educação) - Universidade Estadual de Campinas, Campinas, 2014.

SOUZA, E. L. Umbigos enterrados: corpo, pessoa e identidade Capuxu através da infância. 2014. 422 f. Tese (Doutorado) - Centro de Filosofia e Ciências Humanas, Universidade Federal de Santa Catarina, Florianópolis, 2014.

SOUZA, M. L. A. "Ser quilombola": identidade, território e educação na cultura infantil. 2015. 265 f. Tese (Doutorado em Educação) - Universidade Estadual de Campinas, Campinas, 2015.

VASCONCELOS, T. M. Aonde pensas tu que vais? Investigação etnográfica e estudos de caso. Portugal: Porto Editora, 2016.

VIEIRA, D. C. S. C. A imaginação na produção narrativa de crianças: contando, recontando e imaginando histórias. 2015. 141 f. Dissertação (Mestrado em Educação) - Universidade de Brasília, Brasília, 2015. 